\title{
Analisando a produção do conhecimento
}

Régis Henrique dos Reis Silva

Editor do dossiê Análise da produção do conhecimento

$\mathrm{N}$

o momento em que nos deparamos, nas políticas educacionais, com teorias da educação em bases liberais, conciliando e/ou alternando as concepções produtivista e humanista de caráter multicultural (DI GIORGI, 1996; SAVIANI, $2011^{1}$ ) com o próprio contexto ideológico de "Recuo da Teoria", ou melhor, de uma proposição teórica de caráter pragmático com foco na ação (saber fazer²), avaliamos que se faz necessário identificar necessidades, prioridades e perspectivas de desenvolvimento do conhecimento produzido nas áreas de educação e educação física no Brasil.

Nesse sentido, os estudos do tipo "meta-análise" ou de "pesquisa da pesquisa" tornam-se fundamentais no esforço de busca de indicadores de qualidade da pesquisa em educação e educação física, pois fornecem elementos que ajudam a compreender as formas de elaboração da pesquisa educacional e sinalizam perspectivas para o desenvolvimento e a consolidação das linhas de pesquisa nos programas de pós-graduação. Além disso, subsidiam a definição de estratégias para o aprimoramento da formação profissional e científica do educador nos cursos de graduação e programas de pósgraduação.

Por tudo isso, acreditamos que o presente dossiê, intitulado Análise da produção do conhecimento, contribuirá significativamente para o debate e a compreensão dos rumos da produção do conhecimento nas áreas de educação e educação física. O dossiê, preparado pela

${ }^{1}$ DI GIORGI, C. A. G. Concepções do Banco Mundial e outros organismos internacionais sobre educação: problemas e contradições. Revista Nuances, v. II, out.1996. Unicamp, SP. SAVIANI, D. História das ideias pedagógicas no Brasil. 3. ed. rev. 1a reimpr. Campinas, SP: Autores Associados, 2011. Coleção Memória da Educação. 474 p.

${ }^{2}$ Conforme Moraes (2004) as reformas educacionais trazem, junto à prática do saber fazer, uma pedagogia que desvaloriza o conhecimento escolar e uma epistemologia que deprecia o conhecimento teórico, científico e acadêmico. (Cf. MORAES, M. C. M. de. Iluminismo às avessas como contexto da pós-graduação no Brasil. Educação Unisinos. vol. 5, n. 9, p. 79-101, jul/dez. 2004). 
linha Epistemologia e Teorias da Educação (Episteduc) do Grupo de Estudos e Pesquisas em Filosofia da Educação (Paideia) da Universidade Estadual de Campinas (Unicamp), inclui os seguintes textos: O método lógico histórico nas análises epistemológicas: a experiência brasileira no campo da educação física, de autoria de Sílvio Sánchez Gamboa e Márcia Chaves Gamboa; Determinações históricas e epistemológicas mediante relações contraditórias dos PNPG, de Kátia Oliver de Sá, Moisés Henrique Alves e Ivson Conceição Silva; Análise da produção científica das regiões sul e nordeste do Brasil: a iniciação esportiva na Educação Física escolar de Camila da Cunha Nunes e Adolfo Ramos Lamar; Caracterização da produção dos docentes/pesquisadores dos cursos de educação física da Paraíba, de autoria de Lívia Tenório Brasileiro, Roseane Barros da Silva e Dianderson Carlos Costa Silva; A produção científica da pós-graduação em educação na Universidade Pedagógica e Tecnológica da Colômbia, de Reina Del Pilar Sánchez Torres; Construção e aplicação de matrizes bibliométrica e epistemológica para análise do referencial freireano no Ensino de Ciências, de Gabriela Zauith e Maria Cristina Piumbato Innocentini Hayashi; e Estudo bibliométrico e epistemológico das teses de doutorado do PPGEUFSCAR (1993-2005), de Márcio Coelho e Maria Cristina Piumbato Innocentini Hayashi.

Na seção Artigos, este número de Filosofia e Educação reúne textos de Jorge Luis D'Ávila e Getulio Lima (Propedêutica à epistemologia do método em educação e a dialética da protoforma do lugar do discurso), José Antônio Feitosa Apolinário (Algumas considerações sobre a interdependência entre democracia e educação no pensamento ocidental) e Maria das Graças de Almeida Baptista (A educação crítica como possibilidade educacional).

Fecham a presente edição, na seção Pesquisas, os autores Gilberto Lacerda Santos e Raquel de Almeida Moraes, que comparecem com o texto $A$ educação na sociedade informacional: anotações provenientes de uma pesquisa de natureza filosófica.

Desejamos a todos uma leitura proveitosa. 